Sección Uno: Ensayo

Retos y Experiencias en la Construcción de Paz

\title{
Una mirada adentro de nosotros mismos para conocer al otro diferente que nos acompaña. La interculturalidad del Colegio San Bernardino. $^{1}$
}

A look inside ourselves to know the other different who join us. San Bernardino school's interculturality

\author{
Blanca María Peralta Guachetá \\ Colegio San Bernardino \\ bmpguacheta@gmail.com \\ Jhon Edinson López Garzón \\ jhonedinsonlopezgarzon@gmail.com
}

\section{Resumen}

Reconocemos la historia del territorio ancestral muhysca de Bosa, así como las historias de los pueblos que lo habitan o llegan de otras latitudes a habitarlo, como parte fundamental de los tejidos interculturales que hemos trenzado por quince años en el colegio San Bernardino; este es el lugar a donde confluyen a diario los niños y niñas de comunidades indígenas, afrodescendientes, campesinos, entre otros. Las itinerancias se convirtieron en práctica educativa que nos conduce por las memorias ancestrales para encontrarnos con nosotros mismos. En el consejo de etnias sembramos pensamientos, tradiciones y palabras, un espacio para construir juntos lo que somos.

\begin{abstract}
Abstrac
We recognize the history of the ancestral muhysca territory of Bosa, as well as the stories of the people who live there or come from other places to inhabit, as a fundamental part of intercultural tissues that have stranded for fifteen years at the Colegio San Bernardino. This is the place to come together daily for children of indigenous communities, Afrodescendants, peasants, among others. Itinerancias became educational practice that leads us
\end{abstract}

${ }^{1}$ Recibido: 24/07/2018 Evaluado: 01/08/2018 Aceptado: 15/09/2018 
through the ancestral memories to find ourselves. On the advice of ethnic sow thoughts, traditions and words, a space to build together what we are.

Palabras clave: Educación intercultural, Pedagogías contemporáneas

Keywords: Intercultural education, Contemporary pedagogies

Bosa es una de las 20 localidades de la ciudad de Bogotá, Colombia, está ubicada en la periferia al sur-occidente de la urbe, esta puede ser reconocida por su contexto de cambios y permanencias, de pobladores originarios y venideros. Es allí donde se inscribe el colegio San Bernardino en territorio ancestral muhysca. Los Muhyscas son un grupo de indígenas originarios de este territorio, habitantes de estas tierras desde antes de la llegada de los europeos a América. Bosa es un espacio donde convergen hoy los diferentes actores sociales, tanto de este territorio, como procedentes de otras regiones del país; dotándolo de particularidades multiculturales e interculturales.

El colegio tiene algo más de 100 años, pues, alrededor de 1913 nace legalmente con el nombre de Escuela Rural de San Bernardino. Asistían niños que cursaban varios grados de la escolaridad primaria y todos se disponían en ese mismo salón y con una sola maestra. Es importante a señalar que, este salón no tenía ni cercas, ni muros que impidieran la interacción con la comunidad y el territorio circundante, en el descanso los estudiantes podían ir a sus casas a tomar onces y volver para continuar con las clases. Nuestra escuela, sin embargo, ha ido sufriendo la transformación normal de las escuelas de la periferia bogotana, hoy ya es un colegio con una infraestructura mucho más completa, encerrado por muros de concreto al estilo de toda escuela clásica; cuenta con dos mil estudiantes, sesenta maestros para las dos jornadas escolares existentes, un edificio de tres pisos, veintisiete salones, los 12 grados de la escolaridad obligatoria en nuestro país y muchas de las "ventajas" de la modernidad educativa.

Parece ser que hemos venido naturalizado el hecho de concebir la escuela como un espacio cerrado que aísla bruscamente a las personas de la cotidianidad de la vida social de su territorio, el niño deja de estar mezclado con los adultos y deja de conocer la vida directamente en contacto con ellos (Valera, J;y Álvarez, F. 1991). Con la escolarización se intenta regular y controlar la funcionalidad interna del espacio escolar en el que la vida, adentro, corresponde a las lógicas propias de la escuela clásica occidental, se da entonces un largo proceso de encierro de los niños, práctica que continúa hasta nuestros días y que está lejos de superarse dados los controles sobre los tiempos, los desplazamientos, las actividades, los movimientos de los cuerpos, y un largo etcétera. Que describen el uso de dispositivos para hacer más dóciles a los sujetos en formación al interior del claustro escolar (Foucault, M. 2002).

El San Bernardino (desde ahora San Berno). también ha cambiado con las nuevas generaciones que conviven hoy allí. Ahora son mucho más diversas y su sentido de apropiación territorial es diferente al de las primeras generaciones; la relación entre escuela y territorio es distante, así como con los elementos naturales que rodean al colegio, por ejemplo el río, “...donde ya nadie arrima por lo apestoso que se ha vuelto, es más, ya no queda donde cultivar, para que se asomen a la tierra y sepan que es eso, por eso es que no 
sienten como suyo las cosas" (Villamizar, 2012).De otro lado, hay una gran cantidad de niños y niñas provenientes de tierras de la costa pacífica y atlántica colombiana lo que hace que sea muy marcada la presencia afrodescendiente en el colegio. Sin embargo, no sólo de estas regiones provienen nuestros niños y niñas, tenemos estudiantes de casi todos los rincones de Colombia, que como víctimas de las diferentes modalidades de desplazamiento forzado han tenido que establecerse en Bosa encontrando aquí alguna estabilidad.

Los maestros hemos ido entendiendo que los niños y niñas ven al colegio como su segundo hogar, algunos, los que dejaron sus tierras, la asocian con la escuelita de la que vienen allá en sus regiones. Era su cotidianidad compartir con sus compañeros y maestros de maneras muy vivenciales. Pues bien, ahora van al San Berno porque quieren, a pesar de sus condiciones de desplazamiento, así que, debemos aprovecharlos al máximo para hacer algo junto con ellos.

Es ese el inicio de cómo los profesores empezamos a pensar qué podíamos hacer para que los estudiantes (y nosotros mismos) le halláramos sentido a lo que hacemos en la escuela. Consideramos como un camino posible aquel relacionado con la perspectiva intercultural, dado que este colegio vive una diversidad cultural, similar a la de toda Colombia, porque como dice Vigil, N. (2006) "...la interculturalidad es a la vez concepto y una realidad que comprobamos día a día..." precisamente así es cotidianamente en el colegio. Podemos decir también que, suponer la Interculturalidad como desarrollo armónico entre las culturas es nuestro ideal.

Iniciamos este camino en 1999, en medio del reconocimiento legal que el Ministerio del Interior le hacía al cabildo de la comunidad indígena muhysca en Bosa, una figura administrativa que le otorgaba, por fin, una posibilidad de asumir su autodeterminación como pueblo indígena. Comenzamos a caminar con esta comunidad y así planteamos, algunas iniciativas como: Rewoayabtyba (Panqueba, J. 2006) medio por el cual fue evidente para toda la comunidad educativa la riqueza cultural que teníamos en frente y que no habíamos reconocido. Luego con Muiskanoba (Panqueba, J; Peralta, B; Huérfano, A. 2005) reconstruimos la historia de los colegios San Bernardino, La concepción y Leonardo Posada, de la localidad de Bosa. Con esta indagación confirmamos que era desde las vivencias presentes y pasadas de la diversidad étnica y cultural que se podía construir "otra” escuela.

Desde estas investigaciones iniciamos la conceptualización sobre la interculturalidad en la escuela y desde la escuela en nuestro territorio. Como resultado de los análisis desarrollados, a través de las itinerancias por los territorios y el tejido de ideas, pensamientos y afectos, definimos que interculturalidad es: el tejido que podemos trenzar entre los diversos territorios que cada comunidad pueda tener, o en los que pueda estar, vivir, pensar, o por los que pueda recorrer. De otro lado entendemos que el territorio es: ser lugar, espacio y centro, es la piel misma. Para MuisKanoba los conocimientos se construyen desde los patrimonios legados por las diversas culturas y/o pueblos ancestrales y actuales. Fundamentalmente: somos Territorio. (Panqueba, J. Huérfano, A. 2006)

Sabiendo que somos territorio, dimos los siguientes pasos hacia la indagación por la memoria de la llegada al San Berno de los profesores y algunos estudiantes; en el proceso denominado: San Bernardino: Territorio de Aprehendizajes, Palabras, Afectos y Barro, (Ortiz, J. Peralta, 
B. 2008), encontramos que estas historias determinaban en gran parte la forma de ser y estar en el colegio de maestros y estudiantes; pues, muchos maestros tenían imaginarios muy diferentes del lugar al que irían a trabajar, nos dimos cuenta que pesa el estigma de ser un lugar peligroso; de hecho los medios de comunicación alimentan con su amarillismo esos miedos, creando de esa manera un tipo "de 'sentido común' de quienes habitamos en la ciudad, las periferias albergan toda suerte de situaciones sociales desfavorables. Entonces vienen imágenes de robos, drogadicción, maltrato familiar, pandillas juveniles y un largo etcétera que en conclusión sugiere peligro.” (Ortiz, J. Peralta, B. 2008)

Nuestro trabajo se ha centrado fuertemente en la perspectiva intercultural, pero no en la interculturalidad de los que se soportan o toleran pasivamente las diferencias y las desigualdades, más bien la interculturalidad critica de los que aprenden los unos de los otros, con el ánimo de fortalecer los referentes identitarios propios y de sus territorios, para luego, participar activamente en proponer alternativas a las tensiones y conflictos que se presentan en el diario vivir de la comunidad escolar. Esta perspectiva está plenamente soportada en la memoria de quienes hacemos parte de la comunidad educativa y de quienes han vivido en el territorio donde está el colegio. Hemos desarrollado nuevas formas de aprovechar educativamente la diversidad cultural y constituimos nuestras propias pedagogías (Panqueba, J. Peralta, B. 2009) reconociendo que lo común a todos es precisamente la diversidad, y que ésta, ha de ser tenida en cuenta en los diseños y propuestas de intervención educativa, porque consideramos imprescindibles para la construcción de una sociedad "otra" desde la escuela (López, J. 2012).

A partir del año 2012 implementamos diversas experiencias pedagógicas; pero, además, nos preguntamos, ¿cómo podemos comunicar eso que somos? y ¿cómo comunicamos esas construcciones que día a día hacemos de nosotros mismos? Fue así como nació el Consejo de Etnias como un espacio de construcción colectiva de lo que somos.

En esencia lo que hacemos es propiciar cambios en el desarrollo de la cotidianidad de la escuela. Aquella que reprimía el pensamiento ancestral en otros tiempos, hoy lo está recuperando, fortaleciendo. Superamos el prejuicio de la modernidad respecto a la escuela, en que se argumenta que a esta no acceden los saberes sociales en sentido general como concepciones, cosmovisiones, prácticas culturales, sino solamente la filosofía, la matemática, la química y la ciencia. Intentamos construir una sociedad más autóctona, más cercana al proyecto de vida que llevábamos hasta que irrumpió en nuestros territorios ese choque violento entre lo europeo y lo nuestro, sumándonos al esfuerzo de un proyecto social y político en Latinoamérica; el despertar de los pueblos por la recuperación de lo propio.

En este sentido, creemos en la necesidad de revitalizar la Interculturalidad como una oportunidad que puede brindar mayores posibilidades de concretar transformaciones reales con miras a la des-colonización y superación de las condiciones asimétricas que agudizan y perpetúan las desigualdades sociales, económicas y culturales, que luego se manifiestan de diversas maneras en la escuela, la discriminación, el racismo y menosprecio de las comunidades diversas.

Teniendo en cuenta lo anterior, es pertinente para la vida cotidiana en la escuela, la interculturalidad como acción pedagógica, por brindar la posibilidad de aprender de otras 
perspectivas de mundo, así como de alternativas de vida, encontrando en medio de las diversidades lo común a todos como seres humanos y colombianos.

Los estudiantes encuentran en el Consejo de Etnias la tranquilidad de ser, estar y hacer desde su esencia como sujetos con identidades raizales. (Al usar el término raizal asociado a las dimensiones del sujeto, intentamos re-valorar el principio de origen de los pueblos ancestrales, para quienes es fundamental la relación con la tierra y anclan a ella su propia existencia. El uso de este concepto surge a partir de reflexiones sobre qué tipo de sujeto intercultural formamos en el Consejo de Etnias; entonces entendimos que los niños y niñas además de pertenecer a una etnia clara, afrodescendiente o indígena, comparten el vínculo afectivo con la tierra y a partir de ahí se relacionan con ella de una manera muy particular al resto de los niños y niños mestizos. Poseen sensibilidad y disposición para valorar sus tradiciones culturales y la enraízan en el territorio donde se encuentren) La intención de que exista un espacio libre en el que se dé un encuentro intercultural, es que sea a través del diálogo de saberes, el intercambio de vivencias, el trabajo colectivo, que valoramos y resignificamos los valores propios, las memorias de nuestros pueblos ancestrales, reencontramos nuestras raíces, tanto de indígenas como de afrodescendientes. (López, J. 2012)

Un elemento para tener en cuenta es que, la escuela es un campo de confrontación y violencias simbólicas, pues allí confluyen sujetos que se presentan de antemano como antagónicos, por ejemplo, se parte del hecho de que los maestros son sujetos declarados como sabedores y los otros, los alumnos, como confesos ignorantes, estableciendo entonces la asimetría del saber (Serna, 2004) con el que se instala también, la asimetría de poder, detonando tensiones y conflictividades que obstruyen diálogos y acercamientos entre quienes están dispuestos a enseñar y aquellos que quieren aprender, porque este tipo de asimetrías restringen la posibilidad de reconocerse como sujetos que pueden relacionarse de forma horizontal en la que pueden aprender y enseñarse juntos.

Dimos los primeros pasos con el Consejo, con 120 niños y niñas de entre 7 y 15 años, de comunidades indígenas y afrodescendientes, con los que nos encontramos en y desde las ignorancias que teníamos de nosotros mismos y hemos ido descubriéndonos, caminando por varios senderos territoriales en los que indígenas y afrodescendientes nos contamos cuentos de los abuelos y abuelas para hallar en la tradición oral la fuente de los saberes milenarios.

Cartografiamos juntos, maestros y estudiantes, nuestras memorias para inscribir en el territorio e ir tejiendo colectivamente las cotidianidades, las vivencias, los afectos, los aprendizajes que nos brindan la tierra, nuestros encuentros y desencuentros con los pobladores, entre otros saberes. De esta manera también damos sentidos y significados nuevos a la forma de interrelacionarnos con los elementos que nos rodea, también simbolizamos el territorio a partir de lo que contemplamos en las itinerancias por el territorio ancestral, aquellas que se han convertido en aulas abiertas llenas de vida.

Expresamos a través del arte el pensamiento legado de nuestros pueblos en las pictografías y petroglifos que nosotros re-elaboramos para actualizar las huellas de las presentes generaciones; aprendiendo a hilar la sabiduría ancestral con la que construimos en el presente; en el Consejo de Etnias también hemos seguido los pasos de los movimientos 
hechos danzas tradicionales de nuestras culturas y escuchamos los mensajes en la música de la naturaleza, interpretada con quenas y tambores. Colectivamente construimos conocimientos propios de los andes y de las costas, viajamos en los cantos familiares por las regiones de Bacatá (Nombre original de la ciudad de Bogotá en idioma Muscubum de la comunidad muhysca) y Colombia.

Exploramos las ciencias botánicas y medicinales de las plantas para curar el cuerpo y alma; los estudiantes les preguntan a sus abuelos para recordar conocimientos adquiridos a través de la experimentación constante; pues con-sentir las plantas hace que nos comuniquemos con sus esencias, sus fragancias, sus sabores, prácticamente con todas sus características y propiedades; con los abuelos aprehendimos a reconocer las bondades que nos brinda la tierra, nos dimos cuenta que en sus jardines existen herbarios vivos, casi farmacias naturales y los estudiantes accedieron al saber del uso práctico de estas medicinas ancestrales.

En el Consejo de Etnias hemos tejido lazos de amistad y solidaridad tan fuertes, que tenemos una familia extensiva en el san Berno al estilo afrodescendiente y armonizamos la comunidad con rituales a la manera de los indígenas, de hecho, el juego ha sido uno de esos elementos vitales del grupo de niños y niños en el Consejo, que se ha ritualizado como practica necesaria para propiciar encuentros interculturales entre los estudiantes y nosotros los maestros, en este ritual participan todos y todas; el juego se convirtió en un momento de compartir la alegría que sentimos de estar acompañados, es donde tiene lugar el cuidado del otro, es el tiempo de construir memorias con valor y significado, es la bienvenida a los niños nuevos, es un saber ancestral que se hace práctica cotidiana.

Esta propuesta posee algunos principios constitutivos en los que se involucra los saberes populares y ancestrales que cada uno de los estudiantes y sus familias; tiene igualmente en cuenta el contexto circundante, la historia del territorio, entre otros aspectos para construir desde allí una sociedad en donde ellos mismos sean actores principales del devenir educativo como sujetos históricos y políticos que son, intentando superar la colonización modernizadora que heredó la institución escolar.

A lo largo de esta labor de educación intercultural nos hemos dado cuenta, de que el Consejo de Etnias ha adquirido ciertas particularidades que es relevante señalar: en este espacio valoramos los saberes de nuestros ancestros cercanos y lejanos; propiciamos de esta manera un encuentro con la sabiduría legada por generaciones en nuestras familias, sabiduría que se actualiza en nuestras cotidianidades y el territorio constantemente cambiante. Revivimos principios comunitarios, como la reciprocidad, ya que ofrecemos nuestros esfuerzos, pensamientos, afectos en el trabajo comunitario; valoramos la palabra porque nos da entendimiento sobre la existencia y esencia del otro, la escuchamos con atención y respeto para tejer juntos pensamiento.

En cuanto a la participación de los estudiantes en este proceso, hemos determinado que sea de carácter libre, valorando la libertad como principio de vida; son los chicos, quienes deciden si asisten o no al Consejo, dándoles la posibilidad de ejercer su libertad y determinación como sujetos autónomos; no condicionamos su asistencia con notas o recompensas de ninguna clase, sin embargo, es claro que allí encuentran la satisfacción de 
ser ellos mismos y de aprender de sus propias familias, del territorio y de sus culturas, por eso siguen asistiendo a los encuentros.

Con persistencia hemos logrado nutrir y fortalecer nuestras identidades familiares, comunitarias, territoriales, étnico-raizales; y de paso que los maestros no solo reconozcan la diferencia cultural de sus estudiantes, sino que comprendan ahora que existen aprendizajes más allá de las asignaturas, que hay aprendizajes y enseñanzas que tienen que ver directamente con los orígenes de esos estudiantes con los que comparten a diario. Entonces podemos decir que hemos posicionado el Consejo de Etnias como un escenario legítimo de construcción de saberes ancestrales dentro del San Berno, dentro de la escuela estatal. Mostramos que es posible que la escuela clásica puede acoger los saberes tradicionales de los pueblos ancestrales y hacer de ellos una posibilidad de pensarse y ser diferente en la ciudad.

Venimos potenciando la formación de un tipo de sujeto que es histórico y político al contemplar la posibilidad de incidir en cómo se hace y cómo se construye cotidianamente, no cualquier historia, sino su propia historia; la del sujeto que participa diariamente de los contextos y territorios donde se desarrolla su vida y el quehacer educativo, ahora son los niños y niñas quienes tienen una fuerte incidencia en el colegio San Bernardino porque son valorados y se les reconoce, no solo como indígenas o afrodescendientes, sino se les tiene en cuenta como interlocutores válidos en la construcción colectiva del acontecer educativo intercultural.

En el San Berno los maestros nos dimos cuenta que debemos mostrar la realidad, no solamente como conceptos en abstracto, sino como espacios para el despliegue de los sujetos en formación, al realizar proceso itinerantes por el territorio circundante les estamos dando la posibilidad de que se adquiera un sentido de la historicidad diferente a la que ha dominado el escenario educativo; constituimos desde el Consejo de Etnias con nuestros procesos abiertos a la cotidianidad, un nuevo sentido de la historicidad, el de situarse en el tiempo para establecer una relación dialéctica entre sujeto y la historia, su historia, porque entramos en contacto directo con la realidad propia del territorio y de la comunidad familiar y educativa. El sujeto histórico e intercultural es capaz de actuar sobre la realidad para transformarla, sin perder de vista que ésta es a la vez múltiple por lo local y global de sus configuraciones.

La creación de espacios interculturales reales y participativos en la escuela rompe con la hegemonía del poder y la verticalidad de este, impulsa debates y confrontaciones para resolver las tensiones entre estudiantes y maestros, pero más allá de los sujetos, confronta los procesos epistémicos de la hegemonía y los de los pueblos originarios, así como sus formas divergentes de ver, sentir, de hacer, y de existir en el mundo. Es necesario resolver las contradicciones que recaen en la escuela entre la colonialidad representada, muchas veces, en los maestros como portadores de saberes disciplinares occidentales y los saberes ancestrales que conservan los estudiantes y sus familias como herederos de pueblos originarios, saberes que se evidencian en prácticas cotidianas como la culinaria o sazón propia a sus regiones de origen, dialectos y expresiones orales, narrativas y memorias familiares, sonoridades y pasiones musicales, un largo etcétera; son saberes entremezclados entre lo popular y ancestral, pero que ellos mismos subestiman inocentemente. A través de estos diálogos interculturales podemos sensibilizarnos como maestros sobre la urgencia de 
cambiar y flexibilizar los currículos para dar paso a otros saberes y perspectivas de mundo que también están presentes en la escuela (López, J. 2018).

En el espacio escolar del San Berno, se intenta potenciar los procesos de identificación con lo propio, o sea, reconoce el valor de su procedencia, de su territorialidad y del legado familiar e histórico que poseen los niños. Buscamos en el colegio con el Consejo de Etnias potenciar las capacidades recreadoras y creativas de los estudiantes para que se sientan orgullosos de lo que son: herederos de un acervo cultural valioso del que no tendrían por qué sentirse avergonzados, sino por el contrario, son portadores y portavoces de una riqueza de saberes y conocimiento propios que se convierte luego, en un motivo para superar los estados de discriminación que la sociedad "mayoritaria" les impone.

En el San Berno se ponen en dialogo las diversidades culturales a través del Consejo de Etnias, entre otras experiencias, adquiriendo características insurgentes que potencia lo simbólico cultural de lo Indígena y lo Afro, abriendo espacios contra-hegemónicos con procesos pedagógicos que tienen el ánimo de tejer afectivamente un sentimiento de solidaridad que hace a los participantes ser y sentirse en comunidad, contrarrestando la individualización y la racionalización que pretende, generalmente en la escuela clásica, instalar en la psiquis social homogenizando cualquier diferencia para constituir su proyecto occidentalizante; en el San Berno se trata más bien de fortalecer la dimensión política y espiritual que tiene la subjetividad y la afectividad de cada sujeto que hace parte de la comunidad educativa, a fin de poner corazón a un diálogo verdaderamente intercultural (Maldonado, A. 2011).

Finalmente y después de resumir la vida tejida en el San Berno, es decir de realizar esta revisión de la memoria intercultural que construimos, podemos decir que compartimos elementos comunes como pueblos raizales (El maestro Orlando Fals Borda nos presenta una perspectiva decolonial y liberadora para la construcción de una sociedad basada en lo propio, fundamentada en reconocer como comunes los valores y principios de nuestras comunidades afro e indígenas; quienes echan raíces para mantener vivas sus tradiciones. Y vemos la posibilidad de que sea a partir de retornar a nuestras raíces originarias que logramos despertar las memorias guardadas en nosotros mismos), (López, J, 2012) que somos sensibles frente al territorio, a las vidas de los otros, a las historias y vivencias que nos hacen entender al otro y hacer que el otro habite en mí; nos hemos fortalecido y damos pasos firmes y seguros en este camino a la construcción de una cultura de la diversidad, de paz y armonía entre los pueblos de nuestra Colombia.

También es importante mencionar que cuando realizamos nuestros rituales de celebración como el día de la Afrocolombianidad, 21 de mayo, o el día de la Interculturalidad, 12 de octubre, nos sentimos como parte del tejido familiar y educativo del San Berno, esto es, vivimos y compartimos esfuerzos, ideas, proyecciones, sueños, saberes, tradiciones; estos rituales nos llenan de fuerza y esperanza porque cada vez somos más los que despertamos y sentimos el llamado de la madre tierra, el Consejo de Etnias es semilla que crece con el cuidado de todos y cada uno de nosotros. Sabemos que es mucho lo que nos falta crecer como comunidad intercultural, seguimos dando pasos tranquilos y seguros hacia la consolidación de esta propuesta "otra" que, dé valor a la sabiduría de nuestros pueblos raizales, quienes nos enseñan a aprender y aprendemos de ellos para enseñar. 


\section{Referencias}

Foucault, Michel (2002). "Vigilar y Castigar. Nacimiento de la prisión”. Buenos Aires: Siglo XXI Editores Argentina

López, J. (2012). Creación de espacios de encuentro intercultural para la construcción colectiva de territorialidad étnica raizal en el colegio San Bernardino de Bosa. Bogotá: Universidad Pedagógica Nacional.

López, J. (2018). Aprender Desde Adentro. La construcción colectiva de una "otra" escuela desde la identidad raizal en el San Bernardino de Bosa. Bogotá: Universidad Distrital José Francisco de Caldas.

Maldonado, Ariruma Kowii. comp. (2011). "Interculturalidad y Diversidad" Quito: Universidad Andina Simón Bolívar.

Ortiz, L. y Peralta, B (2007). San Bernardino. Territorio de aprehendizajes, palabras, afectos y barro. Sistematización del proyecto San Bernarte, recorriendo el territorio muisca de Bosa. Colegio San Bernardino (IED). Programa Escuela-Ciudad-Escuela, IDEP. Bogotá. (En medio digital).

Panqueba, J. (2006). “Experiencia reowayabtyba”. Informe final de la investigación titulada: El "otro" lado de Bogotá: experiencia global de reconstrucción étnica en la comunidad indígena muisca de Bosa, desde sus memorias y cotidianidades. Bogotá, D.C: IDEP, (en línea), disponible en: http://cort.as/-ACJj. Consultado: 21 de enero de 2014

Panqueba, J. y Arturo Huérfano (2006). MuisKanoba: territorios de aprendizajes para cotidianidades interculturales, (en línea), disponible en http://cort.as/-ACJuConsultado: 21 de enero de 2014.

Peralta, Blanca; J. Panqueba y A. Huérfano (2005). MuisKanoba: caminando por el sendero de la memoria educativa del territorio muisca de Bosa. (Informe de investigación), (en línea), disponible en http://cort.as/-ACKD.Consultado: 21 de enero de 2014

Peralta, B. Panqueba, J. (2009). Itinerancias territoriales y patrimonios ancestrales para la escuela intercultural. En VVAA. Premio a la investigación e innovación educativa y pedagógica 2009. (161-179). Bogotá: IDEP.

Varela, J; Álvarez, F. (1991). “Arqueología de la escuela”. Madrid: Las ediciones de la piqueta

Villamizar, Blanca. (25 de 09 de 2012). Entrevista, conociendo el San Berno. (J. E. López, Entrevistador) 